\title{
List of Boxes
}

2.1 Export processing zones 45

4.1 Defining private goods and public goods 90

17.1 Some facts about illegal logging 437

17.2 Laundering illegal logs 438

17.3 Links between bribery and illegal logging 442

17.4 Financing destruction $\quad 449$

17.5 Making financiers pay 450

17.6 Disappointing judicial review 453

17.7 Legal is not sustainable and sustainable is not legal 454

18.1 Dutch laws on pesticides 470

18.2 Drinking water supply in the Netherlands 472

18.3 Global sales of pesticides 474

18.4 Capacity building 476

18.5 DDT and malaria $\quad 477$

18.6 Fewer chemical substances in the EU 479

18.7 Procedure of establishing maximum residue levels 480

18.8 Contamination levels 481

20.1 Expected strategies of pushers and forerunners in Brussels 530

25.1 Types of networks 655 